\title{
FEMI OYEBODE
}

\section{Commentary (on Bhugra: Using film and literature for cultural competence training)}

Bhugra (2003b, this issue) makes the case that fictional narratives can be used as a training resource for cultural competence. At first glance this point is unarguable. Fiction, like the rest of the humanities, records and interprets human experience. In so far as that experience is a reflection of the world of a minority group in society, it can illuminate the underlying cultural beliefs and practices against which a narrative plot is drawn. However, there are innumerable caveats. Fiction, some would argue, is not created for this purpose - that is, it is not created for this kind of utility and does not have instrumental value. Rather, it is created and encountered for its own sake. Furthermore, if we liken fiction to a door with culture as its hinges, the assumption is always that the hinges are in place - in other words, what is most important about culture is usually unremarked upon in a novel. What is obvious is likely to be no more than the conventions that are salient precisely because they are different. Finally, in order for any fiction to work - that is, for it to be true and convincing, conveying something that is interesting and valuable - it must be able to work across cultural beliefs and practices: it must communicate. This presupposes that the shared understanding between writer and reader, irrespective of cultural background, is substantial.

These points are best exemplified by V. S. Naipaul's novel A House for Mr Biswas. Bhugra cites this novel as a work that could serve as a case study. It is set in Trinidad and is the story of an Asian Trinidadian. It includes accounts of his childhood, his marriage, his relationship to his in-laws, and his ambitions epitomised by his wish to live in a house of his own. At one level, it can instruct on the nature of castes and their varying roles and responsibilities, the rituals of birth, the often unstated suspiciousness between Asians of Hindu or Muslim faith; but these matters that are readily identified as deriving from the cultural backdrop are secondary in importance to the universal aspects of the novel, the tragicomic character whose ambitions and longings are unfulfilled because he lacks the wherewithal to bring them to fruition. All intelligent readers will understand this, whether or not they are of Asian origin. Naipaul's novel is a great piece of writing, not because it exemplifies an aspect of expatriate Asian life, but because it uses language with precision to communicate truthfully about human life. If this novel were to be used as Bhugra suggests, then care would have to be taken that undue emphasis is not given to the obvious cultural differences at the expense of the commonality of human motivation and life.

The foregoing discussion has assumed that 'cultural competence' can be taught. By definition, culture includes the beliefs, practices, customs and material artefacts of a people and in general individuals are reared in a culture so as to become more or less competent in it. For example, in British culture most people know how to behave at a church wedding. They know that the father gives away the bride, but the groom is accompanied by a best man who stands to his right. The origins and underlying justification of these particular practices are immaterial. A ready analogy is the distinction between competent language use and the understanding of grammar. The question is whether 'cultural competence' can or should be taught like language, or whether the goal should be to introduce clinicians to the diversity of cultures in Britain so as to raise the awareness of differences and the potential for error in clinical judgement. It could be argued that what Bhugra is advocating is the raising of awareness about cultural difference, and increasing understanding and tolerance of other cultures rather than teaching competence. Fictional narrative can certainly assist in this.

\section{Reference}

BHUGRA, D. (2003b) Using film and literature for cultural competence

training. Psychiatric Bulletin, 27, 427428.

Femi Oyebode Professor of Psychiatry, University of Birmingham, Queen Elizabeth Psychiatric Hospital, MindelsohnWay, Edgbaston, Birmingham B15 2QZ 